\title{
Un obispado bajo la mira del virrey y un prelado celoso de su jurisdicción. Los pareceres del conde de Galve y Manuel Fernández de Santa Cruz ante el Consejo de Indias: 1696 y 1697
}

\author{
Emmanuel Michel FLORES SosA \\ Investigador independiente \\ emichel_900402@hotmail.com
}

Código ORCID: 0000-0002-9825-3318

\begin{abstract}
RESUMEN
En este artículo se estudia la correspondencia del Real Acuerdo de México y del prelado Santa Cruz en torno a algunos acontecimientos ocurridos en la ciudad de Puebla en el año de 1696. Las mencionadas misivas fueron remitidas al Consejo de Indias y representan el último capítulo del enfrentamiento entre ambas autoridades.
\end{abstract}

Palabras clave: Manuel Fernández de Santa Cruz, conde de Galve, Puebla de los Ángeles, conflicto jurisdiccional 
A bishopric under the scrutiny of the viceroy and a prelate jealous of his jurisdiction. The insights of the count of Galve and Manuel Fernandez de Santa Cruz before the Council of Indies: 1696 and 1697

\begin{abstract}
This paper is about the correspondence of the Royal Agreement of Mexico and the bishop Santa Cruz with reference to some developments in the city of Puebla in 1696. These letters were sent to the Council of Indians and represent the last chapter of the confrontation between these authorities.
\end{abstract}

Keywords: Manuel Fernández de Santa Cruz, count of Galve, Puebla de los Ángeles, jurisdictional conflict

\title{
INTRODUCCIÓN
}

De acuerdo con Alejandro Cañeque, uno de los principales rasgos de la historia política de la Nueva España del siglo XVII fue la conflictividad desarrollada entre los virreyes y los prelados. Esto como consecuencia de las peculiares características de la cultura política del reino. Siguiendo a Cañeque, los obispos poseían un centro de autoridad tan poderoso como el centro de poder representado por el virrey, «lo cual hará muy difícil la imposición de la autoridad vicerregia sobre dicho prelado». Asimismo, Cañeque sostiene que, si bien era generalmente aceptado que los obispos eran miembros del cuerpo político de la monarquía, es decir, que debían obediencia y fidelidad al monarca (recordemos que era el rey, bajo el privilegio del regio patronato concedido por la Santa Sede, el que presentaba a los candidatos que ocuparían las diferentes sillas episcopales de los reinos americanos), esto no significó que dicha obediencia y sujeción privara a los prelados de su poder. Es decir, podían ser fieles vasallos del monarca y al mismo tiempo defender enérgicamente 
la autoridad episcopal, aunque esto pudiese significar el enfrentamiento directo y constante con las autoridades representantes del monarca. Aspecto contradictorio que fue expresado en la retórica episcopal donde se justificaba que todas las disposiciones y acciones de los prelados iban dirigidas «al servicio de ambas majestades» No obstante, la defensa de la autoridad episcopal, vuelve a señalar Cañeque, fue vista a menudo como un ataque a la potestad regia o a la de sus representantes, tal y como lo eran los virreyes, quienes procuraron, también, defender a toda costa su autoridad (Cañeque, 2018).

Entre las obligaciones de los prelados, nos señala Cañeque, se encontraba la defensa de la libertad de la Iglesia ante posibles interferencias de las autoridades reales, en particular cuando estas últimas pretendían adjudicarse atributos correspondientes a la jurisdicción eclesiástica, apropiarse de los bienes diocesanos o bien transgredir la inmunidad de la Iglesia. Frente a estas situaciones, los obispos utilizaron todos los medios a su disposición para defender la dignidad de su cargo, ya fueran los más suaves o bien, en caso de ser necesario, el poderoso y eficaz medio de las censuras (Cañeque, 2018). Un ejemplo particular de este tipo ocurrió en la última década del siglo XVII, época que se caracterizó por el estado de carestía que experimentó la Nueva España a consecuencia del deterioro del ciclo de lluvias (Parker, 1981, 2013; Sigüenza y Góngora, 1932; Torres, 1999). Debido a esta delicada situación las autoridades del reino tuvieron que afrontar tres problemáticas. Primero, vigilar el buen abastecimiento de las ciudades; segundo, prevenir y atajar cualquier intento de especulación y regatonería; y tercero, poner mayor atención en la seguridad urbana. Si bien todas las autoridades, tanto seculares como eclesiásticas, coincidían en la necesidad de atender estos tres puntos de manera inmediata, lo cierto es que discrepaban respecto a qué estrategias serían las más indicadas: si debieran aplicarse de manera general o bien adecuarlas a las particularidades de cada provincia y obispado. 
Este aspecto fue el germen de las tensiones entre el virrey de la Nueva España, Gaspar de la Cerda Sandoval Silva y Mendoza, conde de Galve, y el obispo de Puebla, Manuel Fernández de Santa Cruz y Sahagún. Ambos personajes se enfrascaron en un conflicto de varios años en donde se puso en juego el buen abastecimiento y la paz pública de las ciudades de México y Puebla. Mucho más importante es que en este enfrentamiento se pondría en entredicho la libertad de la Iglesia, situación que obligó al prelado poblano a defender la jurisdicción eclesiástica ante los continuos y constantes embates del virrey. En el presente artículo se exponen algunos de los pormenores de dicha confrontación. Sin embargo, lo más relevante y el punto más importante de este trabajo son las representaciones hechas por ambas autoridades al Consejo de Indias en los años de 1696 y 1697, particular que puso fin a este enfrentamiento. En el primer apartado del texto se expondrá de manera sucinta los aspectos generales del enfrentamiento entre el virrey y el obispo poblano, valiéndonos para ello, considerando lo limitado del espacio del que disponemos en el presente trabajo, de investigaciones recientes y no de fuentes primarias. Mientras tanto, el segundo apartado se centrará en exponer el contenido de las correspondencias remitidas por el conde de Galve y Manuel Fernández de Santa Cruz al Consejo de Indias.

\section{A falta de trigo, tensiones sociales y conflictos en los ÁMBITOS DE AUTORIDAD}

Para comprender la relevancia que tienen los testimonios que expondremos en el siguiente apartado es necesario insertarlos en el debido contexto. Es importante señalar que los hechos que se reseñarán a continuación serán descritos desde el contenido de mi tesis doctoral, la cual lleva por título Un dechado de príncipe eclesiástico. Puebla de los Ángeles durante la gestión del obispo Manuel Fernández de Santa Cruz (1675-1699). En concreto de los capítulos 3 y 5, los cuales 
se titulan «La carestía de finales de siglo y el abastecimiento urbano (1691-1695)»y «La defensa de la jurisdicción eclesiástica (16931694)», respectivamente. La decisión de recurrir a esta investigación se debe, en primer lugar, a lo limitado del espacio que nos brinda el presente artículo como para referenciar la considerable cantidad de fuentes primarias utilizadas en la investigación. En segundo lugar, a que no hay otro trabajo que aborde este tema de manera extensa y pormenorizada. Y es que, por sorprendente que parezca, el impacto social, político y económico que tuvo la carestía de granos a finales del siglo XVII en la ciudad de Puebla y su obispado es un tema que no ha sido abordado a profundidad por la historiografía. Hay que señalar, además, que aquellos textos que tocan el tema lo hacen de manera muy limitada. Los trabajos de Juan Pablo Salazar Abreu, por ejemplo, si bien mencionan la hambruna experimentada en el obispado de Puebla en la década de 1690, no ofrecen mayores detalles que den cuenta de las circunstancias particulares experimentadas en la ciudad de Puebla, así como de las acciones emprendidas por Manuel Fernández de Santa Cruz o de los actores que estuvieron involucrados en dicha problemática. De hecho, Salazar Abreu tan solamente se conforma con narrar la situación de carestía en apenas unos cuantos renglones (Salazar Abreu, 2005, 2016, 2020).

Finalmente, en tercer lugar, la determinación por recurrir a la tesis doctoral radica en darle cierto énfasis y protagonismo a las representaciones de 1696 y 1697, documentos que quedaron fuera de la misma tesis doctoral, pero que dan cuenta del conflicto. En este sentido, el presente artículo tiene la intención de presentar, a manera de capítulo complementario, la última etapa del conflicto, el que desafortunadamente no pudo ser incorporado a la investigación doctoral. Por lo tanto, se suplica al lector comprenda la situación y permita el uso de esta tesis como principal referencia sin que ello represente una pérdida de objetividad de nuestra parte.

Pues bien, luego de este paréntesis, procedamos a tratar el tema de nuestro interés. Si bien es cierto que en la problemática de 
la carestía de finales del siglo XVII estuvieron involucradas varias figuras de autoridad, entre las que destacaron el tribunal de la Real Audiencia, el corregidor de México Teobaldo González, el cabildo secular de la ciudad de México (estos dos como principales asesores del virrey), ${ }^{1}$ las órdenes religiosas de Santo Domingo, San Francisco, San Agustín, Nuestra Señora de la Merced y la Compañía de Jesús, así como el arzobispo de México Francisco de Aguiar y Seijas (el cual se interesó por las condiciones materiales de los naturales de la ciudad de México, así como por denunciar las consecuencias negativas que trajo consigo la prohibición del cultivo del trigo blanquillo durante aquella época de carestía), ${ }^{2}$ no cabe duda de que los principales protagonistas de nuestra trama fueron el conde de Galve y el obispo Manuel Fernández de Santa Cruz. Don Gaspar de la Cerda Silva y Mendoza, virrey de la Nueva España desde 1688, se caracterizó por ser un personaje celoso e interesado por hacer valer los derechos del monarca en el reino. En este sentido, una de las principales características del gobierno de este virrey fue su empeño por implementar cierto grado de centralismo. Prueba de ello lo observamos en la administración y distribución de los caudales de la Real Hacienda destinados al fortalecimiento de las defensas militares de Nueva España y su zona geográfica de influencia (el Caribe español y las islas Filipinas) (Gutiérrez Lorenzo, 1993; Celaya Nádez, 2010). Este afán de centralidad lo podemos encontrar, también, en las constantes intervenciones del virrey en asuntos que competían a la jurisdicción de otras corporaciones como la Real Audiencia, principalmente en asuntos de justicia, situación que provocó no pocos sinsabores entre ambas autoridades (Silva Prada, 2007).

1 Biblioteca Palafoxiana (en adelante BP), Mandato del Conde de Galve para que se ejecute la permisión de los trigos cogidos en Atlixco, Libro 32389, Manuscritos, Documento 32389/015, ff. 266f-267f.

2 BP, Correspondencia del obispo al virrey sobre el permiso de sembrar trigo blanquillo, Libro R478, Manuscritos, Documento R478/110, ff. 236f-236v. 
Por su parte, varios investigadores han resaltado el celo de Manuel Fernández de Santa Cruz, tanto por el cuidado espiritual de su rebaño como de los privilegios del poder eclesiástico y sus corporaciones desde su arribo a la diócesis poblana en el año de 1677. Juan Pablo Salazar, por ejemplo, ha resaltado las denuncias que hizo este obispo respecto de los abusos cometidos por los alcaldes mayores en distintas partes de su obispado, la defensa que hizo de los colegios tridentinos de la ciudad de Puebla frente a los ataques que recibió por parte de la Universidad de México, y de su combate a la embriaguez entre los indios, mestizos, negros y mulatos. (Salazar Abreu, 2005, 2016, 2020). Finalmente, no podemos dejar de lado la labor pastoral de Fernández de Santa Cruz, así como su patrocinio de la ciudad de Puebla. Investigadores como Montserrat Galí e Iván Escamilla destacaron las diferentes fundaciones de conventos y colegios realizadas por este obispo, destacando entre ellas el colegio de María Egipciaca para mujeres públicas, el de San José y el de Santa Teresa para doncellas, así como el convento de Santa Mónica bajo la regla de San Agustín. Destacan igualmente los favores que concedió don Manuel al beaterio de Santa Rosa, al oratorio de San Felipe Neri, a los reales colegios de San Pedro y San Juan, al de San Pablo, al de niños expósitos, y a los diferentes hospitales de la ciudad, entre ellos, el de San Pedro (Galí Boadella, 2001; Escamilla, 2002).

Como podrá percatarse el lector, en ambos personajes se pueden apreciar ciertas similitudes. La más relevante de todas es que ambos estaban interesados en mejorar las circunstancias materiales que se estaban experimentando en el reino, y para ello se valieron de cualquier medio a su disposición. Además, los dos mostraron siempre un enorme celo y afán por llevar a cabo sus proyectos y objetivos. Este particular nos permite vislumbrar, en cierta medida, el carácter de esta dupla, el cual, desde nuestro punto de vista, se caracterizó por ser obstinado y un tanto explosivo, lo cual se verá reflejado en la misma problemática de la carestía. 
Ahora bien, ¿cuál fue la raíz del enfrentamiento entre estas dos figuras de autoridad? Como ya habíamos adelantado, fue el estado de carestía que estaba experimentándose en la Nueva España, de manera particular en los valles centrales, desde inicios de la década de 1690. Las alteraciones en el ciclo de lluvias trajeron como consecuencia la pérdida de las cosechas de trigo y maíz, granos que conformaban la dieta básica de los novohispanos. Mientras que las primeras fueron víctimas de la plaga (el chahuistle), en las segundas el exceso de humedad provocó que las mazorcas no crecieran ni produjeran granos (Sigüenza y Góngora, 1932; Torres, 1999). La pérdida de las cosechas trajo inevitablemente el hambre y, por lo tanto, el incremento de las tensiones sociales en los diferentes asentamientos del reino. A pesar de las diligencias emprendidas por las autoridades con el fin de mejorar el estado crítico de las cosas, sus empeños no rindieron los resultados esperados, particular que ocasionó el estallido de la violencia en diferentes ciudades de la Nueva España, entre ellas la propia corte mexicana (Silva Prada, 2007; Calvo, 2016). Para las autoridades superiores del reino, el tumulto del 8 de junio de 1692 en la ciudad de México se convirtió en un hito de fuerte impacto que los motivó a redoblar esfuerzos con el objetivo de evitar un nuevo levantamiento social de tal magnitud. Por lo tanto, se hacía imprescindible que los almacenes municipales de aquella ciudad estuviesen con la mayor cantidad de trigo y maíz posible para alimentar a toda su población.

En este sentido, el obispado de Puebla jugó un papel protagónico ya que entre los siglos XVI y XVII esta diócesis era reconocida por su gran actividad agrícola, en particular del cultivo de trigo. En concreto, destacaron las jurisdicciones de Acatzingo, San Salvador, Nopalucan, Huejotzingo, Cholula, Puebla, Tochimilco, Tepeaca y Atlixco como las principales zonas en donde se cultivaba y cosechaba el trigo (Contreras, 1993; Paredes Martínez, 1991; Prem, 1978). Era tal la cantidad de granos cosechados que desde la segunda mitad del siglo XVI y hasta finales del XVII, previo al apogeo agrícola 
de El Bajío en el obispado de Michoacán, la diócesis de Puebla fue conocida como el granero de Nueva España. Por lo tanto, no debe extrañarnos que Gaspar de la Cerda, conde de Galve, con el único fin de vigilar el buen abastecimiento de la ciudad de México y contener el malestar de sus vecinos, se empeñara en aprovechar las cosechas poblanas. En este sentido, el virrey emitió, desde 1693, constantes despachos al obispado poblano con el objetivo de trasladar la mayor cantidad de fanegas a la corte mexicana. Sin embargo, las medidas implementadas por el conde de Galve para contener al leviatán mexicano tuvieron un impacto negativo en la diócesis de Puebla, igualmente afectada por el estado de carestía. En específico, se perjudicaba el abastecimiento de las poblaciones de aquel obispado, incluida la ciudad de Puebla de los Ángeles.

Manuel Fernández de Santa Cruz, obispo de aquella diócesis, mantenía la misma preocupación que el conde de Galve. En concreto, que las tensiones sociales generadas por la falta de alimentos ocasionaran un levantamiento tan impactante como el acaecido en México o el de Tlaxcala (urbe mucho más cercana a la ciudad de Puebla y perteneciente a su obispado). Su principal foco de preocupación fue la ciudad de Puebla, principal asentamiento del obispado y sede de la silla episcopal (Gerhard, 1981; Flores Sosa, 2020). Pruebas no le faltaban para sustentar sus temores. Por esas fechas Puebla de los Ángeles era el epicentro de fuertes tensiones sociales ocasionadas por los roces entre los vecinos y el cabildo secular de la ciudad. Asuntos como la falta de agua, la precaria situación de los graneros municipales, la administración de las alcabalas en la jurisdicción urbana (Celaya Nádez, 2010) y el cobro del gravamen de las tres cuartillas (Alfaro Ramírez, 2001) son algunos particulares que amenazaban con provocar un levantamiento popular. De no ser por la intervención personal del obispo en todos estos asuntos las tensiones habrían provocado un estado de terrible violencia. De manera particular, fue muy relevante la injerencia del prelado Santa Cruz en el abastecimiento urbano de la ciudad de Puebla. Ya fuera 
suministrando con el trigo y maíz de las trojes eclesiásticas a la alhóndiga municipal, nombrando un administrador que estuviese al tanto del estado de dicho granero, o bien negociando con los labradores el precio de las cargas. Tal intervención había mantenido a los vecinos de Puebla en relativa paz, pues a pesar de las complicadas circunstancias que se experimentaban en la urbe la población jamás se amotinó (Flores Sosa, 2020).

Por lo tanto, Manuel Fernández de Santa Cruz miraba con recelo las pretensiones del virrey en su afán de trasladar las cosechas de trigo poblano a la ciudad de México, ya que esto implicaría un mayor deterioro de la situación en la jurisdicción diocesana. Si bien no se opuso rotundamente a la extracción de granos de su obispado, al menos esperaba que los despachos fueran los menos posibles y se ejecutasen con la mayor civilidad. En ambos puntos se equivocó el prelado, ya que entre 1693 y 1695 fue constante la presencia de comisionados del virrey en el obispado, algunos de ellos oidores de la Real Audiencia. Personajes como Pedro de Castro, Luis de Monroy, Antonio Cerati y Miguel Calderón de la Barca pasaron a la jurisdicción diocesana de Puebla con el fin de publicar el respectivo mandamiento y recolectar las fanegas de trigo. Tales pretensiones no solo provocaron el temor de la población diocesana ante un posible escenario de escasez, también motivó a los labradores de las comarcas trigueras a evadir las órdenes del conde de Galve usando como estrategia el ocultamiento de las fanegas (Flores Sosa, 2020). En represalia, los comisionados recurrieron al uso de la coerción con el fin de disuadir a los productores de entregar sus cosechas, siendo sus principales armas la imposición de multas y la amenaza de arresto al transgresor. Este particular lo apreciamos principalmente en los agentes Pedro de Castro, Luis de Monroy y Antonio Cerati, comisionados que ejecutaron los despachos virreinales entre los meses de mayo y octubre de 1693.

Como era de esperarse, las acciones de estos tres comisionados provocaron el malestar de la población haciendo que las tensio- 
nes sociales del obispado incrementaran de manera abrupta. Tales circunstancias no pasaron desapercibidas a Manuel Fernández de Santa Cruz, quien en todo momento estuvo al tanto de las acciones emprendidas por los agentes del virrey. El malestar del prelado era evidente ya que sus esfuerzos por mantener la paz en el obispado estaban siendo comprometidos por las pretensiones del virrey. Los enfados del obispo incrementaron aún más al tener noticias de que el conde de Galve pretendía apropiarse también de los trigos que pertenecían a los eclesiásticos, lo que colmó su paciencia. Por lo tanto, emprendió una férrea defensa de su jurisdicción, valiéndose para ello de todos los recursos que tuvo a su disposición. En un primer momento, don Manuel trató de persuadir al virrey de que diese marcha atrás a sus objetivos, alegando que el estado de cosas en el obispado no permitía la realización de constantes traslados sin ocasionar un mayor deterioro social. A través de un considerable número de cartas, el prelado siempre fue enfático al señalar que la cantidad de granos existentes en su diócesis no era suficiente como para abastecer tanto a la ciudad de México como a su rebaño (Flores Sosa, 2020). En este sentido, don Manuel siempre denunció que su feligresía no solo estaba siendo sacrificada para satisfacer las exorbitantes demandas de la corte mexicana, también acusó los atropellos hechos por los comisionados (Antonio Cerati fue el personaje de quien mayores denuncias remitió el obispo). ${ }^{3}$

A pesar de esta situación, el conde de Galve ignoró las denuncias y consejos que el obispo de Puebla le comunicó. Desechó también las advertencias del prelado respecto a la posibilidad de tumulto en aquella diócesis. Ante tal situación Manuel Fernández de Santa Cruz recurrió a métodos más fuertes como la amenaza de

3 Destaca el memorial escrito por Fernández de Santa Cruz con fecha del 2 de octubre de 1693, donde el obispo reprocha al propio Antonio Cerati su comportamiento y modo de proceder. BP, Memorial del obispo de Puebla sobre la defensa de los eclesiásticos a favor de los labradores, quienes tienen que enviar sus cosechas a la ciudad de México, Libro R469, Manuscritos, Documento R469/035, ff. 161f-161v. 
censuras tanto al conde de Galve como a sus agentes. Solo así el virrey comprendió que de continuar con sus afanes se enfrascaría en un fuerte conflicto con Fernández de Santa Cruz. Por lo tanto, suspendió los traslados de trigo a la ciudad de México, al menos por lo que restaba del año 1693. De esta manera, el obispo de Puebla había obtenido una victoria temporal. Sin embargo, el virrey estaba lejos de dar marcha atrás en sus afanes de abastecer a la ciudad de México con los granos de la diócesis poblana. De hecho, ya venía orquestando un nuevo proyecto: la tasación del trigo y sus derivados (harinas y pan). El objetivo de tal medida era fijar los precios de comercialización con el fin de reducir la regatonería. En este sentido, la suspensión temporal tenía por objetivo el disminuir las tensiones existentes entre ambas figuras de autoridad y poder así introducir la medida en el obispado de Puebla. No obstante, tenemos noticias de un nuevo mandamiento de traslado que se realizó en la primera mitad de 1694 por el mencionado Antonio Cerati. Sorprendentemente la comisión fue realizada con menos fricciones que las anteriores, aunque no por ello el prelado dejó de denunciar algunas circunstancias. La más relevante es el primer intento por imponer la tasación de precios en la diócesis de Puebla, medida que fracasó ante las nuevas amenazas de censura (Flores Sosa, 2020).

Este primer fracaso hizo que el virrey se percatara de que, para el éxito de tal proyecto, no solamente era necesario evitar cualquier enfrentamiento con el prelado poblano, también era indispensable que colaborara. Para ello, el conde de Galve formuló una nueva estrategia de acercamiento. Para los siguientes despachos del año de 1694 el virrey comisionaría a un individuo letrado y con gran capacidad de negociación. La misión específica de tal personaje sería, además de realizar el traslado efectivo de las cosechas, la de entrevistarse personalmente con Manuel Fernández de Santa Cruz y suplicarle colaborase con las medidas de las autoridades del reino. El elegido fue el oidor Miguel Calderón de la Barca, quien se trasladó a la ciudad de Puebla a principios de junio de 1694. En un principio, el plan del conde de Galve se estaba realizando con notable éxito. La entrevista de Cal- 
derón con Fernández de Santa Cruz en el palacio episcopal poblano logró su cometido principal: convencer al prelado de colaborar con el Superior Gobierno. Aunque, claro está, bajo la condición de que la intervención y presencia del agente virreinal no ocasionaría mayores problemas en el obispado. ${ }^{4}$ Todo parecía ir bien. La ejecución del despacho virreinal fue realizada por el oidor en diferentes partes del obispado (Puebla, Atlixco, San Salvador y Tlaxcala) sin ningún contratiempo. A través de la emisión de edictos y de algunas cartas Fernández de Santa Cruz garantizó la ayuda de los eclesiásticos en la diócesis. Sin embargo, el prelado no cumplió con todas las solicitudes del comisionado virreinal. Aquellas que don Manuel consideraba que comprometían su autoridad en la jurisdicción episcopal fueron inmediatamente descartadas por el obispo (Flores Sosa, 2020).

No obstante, la impaciencia y determinación del conde de Galve terminaron por comprometer la comisión del oidor. En julio de 1694, a un mes del arribo de Calderón a la diócesis, el virrey ordenó la tasación al precio del pan (14 onzas por medio real) sin previa consulta a su agente. Si bien la medida parece ser evidencia de una genuina preocupación por el bien común, el virrey no consideró el impacto que la misma traería al obispado de Puebla. De hecho, nuevamente hizo oídos sordos a las nuevas exhortaciones de Manuel Fernández de Santa Cruz. No podemos dejar de pensar que el propio virrey había saboteado su propio plan. No solo había comprometido el trabajo de su comisionado en la diócesis poblana, también ocasionó el enfado del obispo. Como voz de profeta, el prelado ahora veía que sus preocupaciones se estaban volviendo realidad. En respuesta a las disposiciones virreinales, los panaderos dejaron de amasar pan alegando que la tasación ocasionaría la ruina de sus negocios. En consecuencia, se incrementaron las tensiones sociales y se llegó a observar en algunos lugares hechos de preocu-

4 BP, Carta del obispo de Puebla al Conde de Galve sobre la presencia de Miguel Calderón en Puebla para adelantar la remisión de trigo eclesiástico a México, Libro R469, Manuscritos, Documento R469/027, f. 148f. 
pación: por ejemplo, en Atlixco, la presencia de pequeños grupos de personas que se movían por las calles de la villa, de tienda en tienda, buscando algún mendrugo. Asimismo, en la plaza mayor se aglomeró una considerable multitud conformada por «muchachos» y la plebe de la villa, quienes al son de la guitarrilla entonaban cánticos incendiarios («Pan queremos, y si no, nos quemaremos»). La protesta verbal dio paso a la violencia cuando un criado del alcalde mayor atlisquense fue apedreado por la muchedumbre, cuando intentó reprenderlos (Flores Sosa, 2020).

Si bien la situación no pasó a mayores, la noticia de estos eventos fue suficiente para que el prelado emprendiese, tal y como lo había hecho en 1693, la defensa de su jurisdicción. El prelado no solo fue más reacio a colaborar con Miguel Calderón, también se opuso rotundamente a la imposición de la tasación, ya que la medida había demostrado tener un efecto incendiario en el obispado. Ante esta situación el agente del virrey intentó disuadir al prelado, pero no tuvo éxito. De hecho, la estrategia implementada por el oidor fue contraproducente. El oidor estaba convencido de que podía ganarse nuevamente la confianza de Fernández de Santa Cruz, y para ello le remitió una representación en la que exponía las razones que motivaban al Superior Gobierno en la ejecución de tales medidas. No obstante, en su afán por argumentar en favor de la tasación, el oidor fue muy descuidado e imprudente. Entre los puntos que trató se encontraba la necesidad de que la autoridad eclesiástica colaborase con el brazo secular, dando a entender que la Iglesia debía sujetarse a las disposiciones de la autoridad civil durante momentos tan críticos como lo era la carestía (olvidamos mencionar que la tasación estaba pensada para ser aplicada tanto entre los seculares como entre los eclesiásticos). No solo eso, Miguel Calderón llegó a insinuar que los eclesiásticos no habían contribuido en nada para mejorar el estado de cosas. ${ }^{5}$

5 BP, Consulta del oidor Miguel Calderón al obispo de Puebla sobre los precios fijos del trigo a los eclesiásticos, Libro R469/030, Manuscritos, Documento R469/030, ff. 152f-154v. 
Como se podrá dar cuenta el lector, estos dos puntos fueron del total desagrado para Manuel Fernández de Santa Cruz. No solo se estaba cuestionando la libertad e inmunidad de la Iglesia, también se le estaba acusando de no poner los recursos eclesiásticos a disposición del bien común. Por lo tanto, respondió a la representación del comisionado, reseñando todas las acciones que había emprendido desde 1691 y demostrando que «el oro de la Iglesia» se había puesto a disposición de la feligresía poblana desde los inicios de la carestía. De la misma forma, sacando a relucir sus enormes conocimientos en derecho y jurisprudencia, don Manuel respondía a Calderón señalando que no existía autor, o legislación, que reconociese la superioridad de la autoridad secular, aunque sí existían testimonios de las represalias de los eclesiásticos frente a los intentos del gobierno civil por transgredir la inmunidad de la Iglesia. ${ }^{6}$ La sutileza en la amenaza que daba don Manuel a su interpelado salta a la vista.

El obispo también remitió carta al virrey. Sin embargo, el tono del mensaje fue mucho más fuerte y directo. Luego de increpar al conde de Galve por todos los avisos y exhortaciones que le comunicó, todos ellos ignorados, Manuel Fernández de Santa Cruz avisaba que defendería la inmunidad eclesiástica con tal celo y dedicación, «que lo haría hasta ver su roquete y sagradas vestiduras teñidas en su propia sangre» (Torres, 1999; Flores Sosa, 2020). En esta ocasión el virrey hizo caso a la misiva del obispo de Puebla. El conde de Galve se percató de que las tensiones entre él y el prelado podrían traer como consecuencia la creación de un poderoso enemigo y detractor para su carrera política, la que de por sí se encontraba inserta en un complejo contexto de incertidumbre, como consecuencia de la problemática sucesoria de Carlos II. Por lo tanto, tomó la decisión de

6 BP, Respuesta al oidor Miguel Calderón de la Barca del obispo sobre los inconvenientes que tienen los eclesiásticos a la tasación del precio del trigo y su escasez, Libro R469, Manuscritos, Documento R469/016, ff. 112f-116v. 
sobreseer el mandamiento de tasación y ordenó el retorno de Miguel Calderón a la corte mexicana. De esta manera se puso freno a una situación que amenazaba con generar un fuerte enfrentamiento entre las autoridades superiores del reino (Flores Sosa, 2020). Nuevamente, la victoria se la llevaba el obispo Manuel Fernández de Santa Cruz. Sin embargo, como se pone en evidencia en las representaciones, la problemática se mantendría en pie durante los siguientes años.

\section{¿Una Ciudad en caos? Las Representaciones del Real Acuer- do y del obispo Manuel Fernández de Santa Cruz sobre el estado de la ciudad de Puebla (1696-1697)}

El día 17 de mayo de 1696, el Consejo de Indias revisó una carta remitida por el Real Acuerdo de México con fecha del 5 de enero de ese mismo año. En dicha misiva Gaspar de la Cerda, virrey de la Nueva España y conde de Galve, y los oidores de la Real Audiencia denunciaban la delicada situación social que se estaba experimentado en Puebla de los Ángeles. Era una carta pequeña pues apenas ocupaba los dos lados de la hoja. Sin embargo, más allá del breve contenido, una de las principales características de esta misiva radica en el tipo de lenguaje que utiliza. Al ser una correspondencia destinada a la autoridad superior de la monarquía española, es evidente que el mensaje debía estar redactado con términos de sumisión, respeto y reverencia (Bravo, 2010). Prueba de ello son los términos ocupados por el Real Acuerdo al dirigirse a su interlocutor (en este caso el monarca). Aparecen así expresiones como «Señor» o «Vuestra Majestad» para dirigirse a la persona de Carlos II, guardando de esta manera la debida deferencia. En cuanto al contenido hay que señalar que la carta va directo al punto: informar de la situación social que experimentaba la ciudad de Puebla y solicitar la aprobación de la autoridad superior para la ejecución de ciertas medidas. En concreto, la misiva da inicio haciendo referencia a la 
comisión encargada al oidor Miguel Calderón, por orden del propio virrey, para que reconociese las cantidades de trigo que había en la diócesis de Puebla-Tlaxcala. Informaba el Real Acuerdo que, como en años anteriores, las diligencias emprendidas por el virrey tenían por objetivo mantener bien abastecida la alhóndiga de la ciudad de México, aprovechando para ello las cosechas del mencionado obispado y «procurando que la sobras que había en unas fuese socorro a las otras y que en ninguna faltasen».

No obstante, continúa la carta, tras haber regresado a la ciudad de México, Miguel Calderón se presentó ante el Superior Gobierno con el fin de denunciar el estado social de la ciudad de Puebla. En concreto, el oidor les informó el haber sido testigo de la insubordinación de la plebe poblana, misma que no fue atajada por las justicias de la ciudad. De hecho, Calderón responsabilizaba al alcalde mayor de la ciudad, Agustín de Lezaca y Urdamibia, de no haber intervenido en el asunto (nunca especificado de manera concreta en la correspondencia), acusándolo de «tímido y poco activo». Por lo tanto, suplicaba al virrey y a los oidores que tomaran cartas en el asunto.

Ante la denuncia de Calderón, prosigue la correspondencia, el Real Acuerdo determinó que debido a la imposibilidad de destituir al alcalde mayor de Puebla — pues el mencionado cargo se encontraba ya comprometido con otros aspirantes - era necesario hacer el traslado de un ministro togado de la Real Audiencia para que fungiese como Justicia Mayor de la ciudad. Argumentaba el Superior Gobierno al monarca que el objetivo de esta determinación radicaba en «que con la autoridad de la persona y puesto» se pudiera contener a la plebe y restaurar la paz en la ciudad. Cabe señalar, además, que el nombramiento de tal ministro no suponía la destitución de Agustín de Lezaca pues, señalaba el Real Acuerdo, el nuevo Justicia Mayor actuaría de manera paralela a la del alcalde mayor. Aseguraba, además, a los miembros del Consejo de Indias que, de no aplicarse la medida, podían «seguirse graves inconvenientes y recelarse alguna turbación», situación que los obligaba a represen- 
tar, tanto a consejeros como al monarca, para que determinase lo mejor. Se puede apreciar la deferencia en el mensaje pues el Real Acuerdo, al sujetarse a las decisiones del monarca y el Consejo de Indias, estaba reconociendo el carácter superior de estas autoridades (Bravo, 2010). De esta manera finalizaba la representación del Real Acuerdo. ${ }^{7}$ Es importante señalar que una copia de esta misiva ha sido publicada en el libro Obispos de Puebla. Periodo de los Austria (1521-1700) de Juan Pablo Salazar. La fecha de esta carta es del 5 de julio de 1696 y fue recibida por el Consejo el 26 de marzo de 1697. Al final de la carta aparece una nota del Consejo en donde se señala la existencia de esta misiva como de aquella del 5 de enero de 1696, lo que pone de manifiesto que un testimonio del informe y solicitud del Real Acuerdo fue nuevamente remitido al Consejo de Indias en fechas posteriores (Salazar Abreu, 2005).

Como se podrá dar cuenta el lector, la representación remitida por el Real Acuerdo es muy concreta y vaga pues carece de detalles particulares que den cuenta de los acontecimientos de disturbios en Puebla. ¿A qué se estaba refiriendo el oidor Miguel Calderón cuando acusaba a la plebe de la ciudad de insubordinación? Es probable que los consejeros reaccionaran con la misma sorpresa ante las noticias que enviaba el Real Acuerdo. No obstante, la falta de detalles respecto a un asunto tan delicado — como el referenciado en la carta - impedía que los consejeros dictaminaran el asunto de la mejor manera posible. El único punto del que tenía fiel testimonio el Consejo de Indias era las mercedes concedidas a las personas de Agustín de Lezaca y Urdamibia, Diego Ponce de León y Miguel Ramón de Nogales para que ocupasen el cargo de alcalde mayor de Puebla, cada uno por cinco años, luego de que se reconocieran los pagos que cada

7 Archivo General de Indias (a partir de ahora AGI), El Real Acuerdo de México informa a vuestra Majestad sobre el mal estado de la ciudad de los Ángeles por los habitantes de la mucha plebe de que se compone, ocasionada de la timidery poca actitud de su alcalde mayor y poco o ningún respeto que se tiene a la justicia, México 346, 5 de enero de 1696, ff. $1312 \mathrm{f}-1313 \mathrm{v}$. 
uno de los interesados realizó a la Real Hacienda (tres mil pesos). Es evidente que era necesario conocer de manera fehaciente la situación social de la ciudad de Puebla. Por lo tanto, los consejeros, con parecer de su fiscal, cuyo nombre no se especifica, ordenaron que el obispo Manuel Fernández de Santa Cruz enviase su parecer sobre este particular y así resolver con base en los testimonios. ${ }^{8}$

Uno de los aspectos que nos parece muy interesante de esta representación, es el argumento principal con que el Real Acuerdo justificó su propuesta. Es decir, el supuesto estado de alteración social que se vivía en la ciudad de Puebla en 1696. Nos resulta llamativo porque las tensiones sociales del obispado de Puebla no fueron del interés del conde de Galve en los años anteriores. De hecho, el virrey había ignorado los constantes avisos dados por el prelado de Puebla sobre la posibilidad de tumultos y motines en su diócesis de proseguirse con sus despachos y comisiones. ¿Por qué el repentino cambio? Es evidente que no hay concordancia en las anteriores formas de proceder del Real Acuerdo y sus más recientes argumentos. Sin embargo, lo que sí deja muy en claro la representación de 1696 es el interés del conde de Galve por tener presencia efectiva en la jurisdicción episcopal poblana. No por nada hacía la sugerencia de nombrar a un ministro togado como Justicia Mayor de la ciudad de Puebla. Se puede interpretar que la intención del virrey al sugerir tal medida era introducir a un funcionario leal a él en el corazón de la jurisdicción poblana. Personaje que, no podemos olvidar, actuaría en conjunto con Agustín de Lezaca, otro agente del Superior Gobierno nombrado por el propio don Gaspar.

Esto también resulta curioso. A pesar de que se responsabilizaba a Lezaca y Urdamibia como el principal responsable del estado social de Puebla, el Real Acuerdo no lo destituyó a pesar de que, ciudad de los Ángeles por los habitantes de la mucha plebe de que se compone, ocasionada de la timide zy poca actitud de su alcalde mayor y poco o ningún respeto que se tiene a la justicia, México 346, 5 de enero de 1696, f. 1313v. 
suponemos, esta era la alternativa más lógica. Candidatos había para sustituir al impopular Lezaca, pues el propio Real Acuerdo reconocía la existencia de algunas personas que habían pagado para ocupar la alcaldía mayor de Puebla después de Urdamibia. No parece muy creíble que el Superior Gobierno careciese de facultades para rescindir cualquier contrato que hubiera con Agustín de Lezaca en vista del «tímido y poco activo» desempeño del alcalde mayor. No se puede dejar de señalar las constantes fricciones entre Lezaca y Urdamibia y el cabildo secular de Puebla como una razón más para relevar al alcalde mayor de su oficio lo más pronto posible (Flores Sosa, 2020). No obstante, por sorprendente que parezca, las autoridades novohispanas optaron por el nombramiento de un Justicia Mayor que actuase de manera paralela a la labor de Lezaca como la solución idónea.

Todo parece indicar que, con la presencia de este nuevo funcionario, se apuntalaría la influencia y autoridad virreinal en la jurisdicción urbana de Puebla, pues en ella estarían presentes dos autoridades fuertemente vinculadas a las redes clientelares del conde de Galve. ¿Existía algún propósito que motivase al virrey a proponer esta medida al Consejo de Indias? Existen bases para responder que sí. Consideramos que el objetivo de tal proyecto radicaba no tanto en garantizar la impartición de justicia en la urbe, sino en contar con un agente que facilitase la ejecución de las disposiciones del Superior Gobierno. Si bien no hay algún señalamiento concreto en las fuentes aquí revisadas, es muy probable que la intención específica sea el garantizar la ejecución de las políticas virreinales en torno a la tasación del trigo y sus derivados, obstaculizadas por Manuel Fernández de Santa Cruz. De esta manera, los comisionados podían contar con el apoyo de las autoridades poblanas directamente nombradas por el virrey, o bien los mismos despachos podrían ser remitidos directamente a estas para su ejecución. Esto con la garantía de que podrían ser aplicadas de manera más efectiva y exitosa. Sospechamos sobre este particular por la intervención de algunos 
personajes envueltos en los traslados de trigo en la denuncia de 1696. Otro factor que alimenta nuestras sospechas es la forma de proceder del Superior Gobierno en este último caso. ¿Por qué el Real Acuerdo se conformó tan solamente con la opinión de Miguel Calderón de la Barca y no solicitó parecer alguno al alcalde mayor, o bien a la municipalidad poblana? ¿Por qué el propio Calderón, estando en la ciudad de Puebla, no recurrió al obispo Fernández de Santa Cruz en vista de la necesidad de una rápida pacificación de la plebe? Más allá de nuestras sospechas, queda claro que el conde de Galve esperaba una rápida resolución por parte del Consejo de Indias y no contaba con que los consejeros solicitasen la opinión del prelado poblano antes de resolver el asunto.

A pesar de la aparente urgencia con la que debía responderse el particular, las comunicaciones entre las autoridades poblanas y el Consejo fueron significativamente lentas. No fue sino hasta el 6 de enero de 1698 que los consejeros revisaron el parecer del obispo Fernández de Santa Cruz, cuya carta está fechada el 25 de mayo de 1697. En contraste con la representación del Real Acuerdo, la respuesta del prelado es mucho más extensa, pues abarca casi las tres fojas completas. Sin embargo, a semejanza de la misiva anterior, la de Fernández de Santa Cruz está redactada en un lenguaje que refleja sumisión, reverencia y respeto, evidencia de que es una carta dirigida a una autoridad superior. En esta carta también aparece el uso de «Señor»y «Vuestra Majestad» para referirse a la persona del monarca. Otro indicio que refleja el carácter de respeto hacia el destinatario es la razón por la que don Manuel redactó su parecer. $Y$ es que el obispo señala, al inicio de su correspondencia, el haber recibido la orden de su Majestad por real cédula del 25 de junio de 1696, para que externase su parecer respecto a las denuncias hechas por el virrey y la Real Audiencia mexicana sobre «la altives de la mucha plebe que la compone y poca actividad del alcalde mayor». Asimismo, en dicha cédula se le ordenaba brindar su opinión respecto a la propuesta del Real Acuerdo de México. En otras palabras, 
el prelado redactaba su misiva en obedecimiento a las órdenes dadas por la máxima autoridad de la monarquía.

De acuerdo con el prelado, el origen del alboroto en la plaza mayor de la ciudad fueron los acuerdos de las autoridades urbanas sobre la prohibición del baratillo y el arresto de un hombre que transgredió tales disposiciones. La detención de este individuo fue realizada por el mismo alcalde mayor. Sin embargo, la acción no pasó desapercibida por los vecinos, en particular por los estudiantes de los colegios jesuitas (San Jerónimo y del Espíritu Santo) quienes suplicaron a Lezaca liberase al prisionero. Ante la negativa del alcalde mayor los estudiantes tomaron represalias. Se dirigieron a la plaza mayor, tiraron la picota y la llevaron a rastras por algunas calles. Por extraño que parezca, don Manuel no proporciona la fecha en la que se llevaron a cabo estos acontecimientos o el número de colegiales involucrados; limitándose a señalar que dicha acción atrajo la mirada de algunos transeúntes, entre los que se encontraba el oidor Miguel Calderón. El prelado no le da la gravedad con la que el Real Acuerdo había calificado esta situación, pues para él este evento no pasó de ser una mera «travesura de muchachos» que fue exagerada por el comisionado. Escribe don Manuel en su misiva que, a pesar de que el acto tan solamente había atraído la curiosidad de unos pocos vecinos, a Calderón de la Barca le causó «tan grave temor que bastó para salirse de Puebla». Fernández de Santa Cruz también refuta los señalamientos que se hacían de la plebe levantada. Sostiene el prelado que las autoridades urbanas impartían los justos castigos a los infractores, siendo la prueba de ello el que los «traviesos estudiantes» habían sido azotados por sus maestros por orden del propio obispo. En este sentido, el prelado da a entender que la impartición de justicia en Puebla no presentaba descuido alguno, procurando él mismo atender la quietud de la población. En este sentido, asegura el obispo, «a vista de tan poca justicia ha estado tan contenida [la plebe] y la ciudad en tanta quietud y paz que no ha habido delito sobresaliente hasta ahora ni más hurtos que los rateros de los indios de ropa y 
gallinas». Aspecto particular que, continúa el prelado, no podía decir de la propia corte mexicana que «con tanta justicia como la Sala del Crimen, corregidor y alcaldes ordinarios, son tan frecuentes [los delitos] que no hay caja fuerte segura, rompiendo los techos por donde entran a las más escondidas recámaras». ${ }^{9}$

Prueba también de este particular, sostiene a continuación el obispo, fueron los acontecimientos de 1692 tanto en la ciudad de México como en el obispado de Puebla-Tlaxcala. Asegura Manuel Fernández de Santa Cruz que, mientras acaecían los disturbios en la corte mexicana y en la ciudad de Tlaxcala y se alteraban los ánimos en las provincias de Cholula y Huejotzingo, no hubo poder que turbara a los poblanos. Expone don Manuel que el motivo de ello era el amor que sentían los vecinos de Puebla por sus obispos, el cual «es tal que la tiene y conservará [a la vecindad] siempre rendida y contenida». Por lo tanto, resultaba innecesario el traslado de un ministro togado a la ciudad para ejercer el cargo de Justicia Mayor, ya que su presencia no garantizaba el apaciguamiento de los ánimos sociales, «pues habiendo una Sala del Crimen en México sucedió el mismo desorden, y aún mayor atrevimiento, pues quemó la plebe la picota el año pasado de 96, retirando a pedradas a Don Manuel Suarez, alcalde de corte». ${ }^{10}$ Por último, Fernández de Santa Cruz reitera que la experiencia había mostrado que la presencia de ministros togados en Puebla no producía algún cambio significativo, ya que en el pasado varios togados habían ocupado el cargo de alcalde mayor «sin que haya mejorado su gobierno». De la misma manera,

9 AGI, El obispo de Puebla responde a una Real Cédula de Vuestra Majestad en que se pide informe sobre la representación que hace el Real Acuerdo de la ciudad de México a Vuestra Majestad, tocante a Puebla y su alcalde mayor, México 346, 25 de mayo de 1697, ff. $1323 \mathrm{f}-1324 \mathrm{f}$.

10 El obispo hacía referencia a los acontecimientos acaecidos en la ciudad de México a principios de 1696, cuando un grupo de estudiantes quemó la picota que estaba en el centro del baratillo como protesta por la aprehensión de un joven (Salazar Abreu, 2005). 
señala que no faltaba mucho tiempo para que Agustín de Lezaca y Urdamibia desocupase el cargo de alcalde mayor y fuese sustituido por Diego Ponce de León, «caballero de espíritu y brío y de las demás prendas que faltan a dicho Don Agustín», ${ }^{11}$ el cual asegura el prelado mantendrá a la ciudad en paz y justicia. ${ }^{12}$ De esta manera Manuel Fernández de Santa Cruz concluyó su parecer.

Cualquiera pensaría que, con base en los testimonios, el Consejo de Indias se apresuraría a dictar sentencia sobre este particular y remitir las respectivas órdenes. Sin embargo, lo cierto es que para 1698 la situación no resultaba tan apremiante. En todo ese tiempo, los consejeros no recibieron nuevas noticias que dieran cuenta de la inquietud social en Puebla más que una copia exacta de la denuncia hecha en enero de 1696. Por lo que debieron suponer que el estado de cosas había mejorado, o bien que nunca fue tan apremiante. Es importante señalar, además, que para esas fechas había ya una nueva autoridad al frente del reino. Juan Ortega y Montañés, obispo de Michoacán, había ocupado el cargo de virrey interino desde el mes de febrero de 1696, luego de que el propio Manuel Fernández de Santa Cruz renunciara a ese mismo nombramiento. Es decir que el nuevo gobernador ocupó el máximo cargo del reino un mes después de que el Real Acuerdo, encabezado hasta ese momento por el conde de Galve, remitiese su representación a la corte de Madrid. Es probable que los consejeros pensaran que los acontecimientos informados no eran más que la evidencia de las fricciones entre ambas autoridades, y que estas habían culminado con el nombramiento del nuevo virrey. Por lo tanto, no era necesario continuar con las

11 A pesar de lo señalado por el prelado, el sucesor inmediato de Agustín de Lezaca y Urdamibia fue Pedro Fernández de Santillán, Caballero de la Orden de Santiago (1697-1699).

12 AGI, El obispo de Puebla responde a una Real Cédula de Vuestra Majestad en que se pide informe sobre la representación que hace el Real Acuerdo de la ciudad de México a Vuestra Majestad, tocante a Puebla y su alcalde mayor, México 346, 25 de mayo de 1697, ff. $1324 \mathrm{f}-1326 \mathrm{v}$. 
deliberaciones en torno a la representación del Real Acuerdo de México. Razón que explicaría la falta de sentencia tras la revisión del parecer del obispo de Puebla, pues el único apunte que existe del Consejo en la correspondencia de Fernández de Santa Cruz es la fecha en que fue revisado, seguida a continuación de la frase «Vista y téngase presente». De esta manera, podemos observar que los consejeros desecharon por completo la propuesta del conde de Galve, antiguo virrey de la Nueva España.

Otra prueba esclarecedora de esto nos la brindan las actas del cabildo secular de la ciudad de Puebla. Y es que, al revisar los registros de los años de 1696 a 1698, pudimos corroborar que ningún ministro togado puso un pie en la jurisdicción poblana para ejercer el cargo de Justicia Mayor. No hay ni siquiera un testimonio de alguna real cédula en donde se notifique a las autoridades urbanas de Puebla sobre la representación del Real Acuerdo. En este sentido, podemos afirmar que las intenciones del conde de Galve acabaron en un rotundo fracaso pues no recibió el respaldo de los consejeros para la aplicación de su propuesta en la ciudad de Puebla. ${ }^{13}$

Sin embargo, más allá de los fracasados afanes del virrey, nos interesa revisar algunos particulares interesantes de la respuesta del obispo. En particular nos causa cierta sorpresa que el prelado haya minimizado las acciones de los estudiantes. Y es que en años anteriores el prelado siempre temió que en Puebla ocurriese cualquier muestra de insubordinación social. Desde que tuvo noticias de los

13 No podemos olvidar, además, los fuertes vínculos que se forjaron entre los prelados y el Consejo de Indias. Sobre este particular, Oscar Mazín señala que los obispos fungieron como miembros honoríficos de ese sínodo. De igual manera, los prelados compartieron con el Consejo una visión contractual del gobierno que ponderaba la legitimidad sinodal frente al avance del poder de los válidos y sus redes clientelares. Como consecuencia, los obispos y sus iglesias, señala nuevamente Óscar Mazín, «fueron objeto del favor del Consejo de Indias en lo concerniente a diversas materias, desde los conflictos de precedencia con los virreyes hasta la designación del arzobispo de México como virrey interino durante periodos inusitados algo superiores a los seis años» (Mazín, 2012a, 2012b). 
tumultos en la corte mexicana y en la provincia tlaxcalteca, Fernández de Santa Cruz se preocupó de que la violencia pudiese propagarse por otras partes de su diócesis. Ya hemos señalado que don Manuel recelaba de que en Puebla pudiese germinar la violencia social como consecuencia de las diferentes problemáticas que se estaban experimentando en la urbe. También hemos mencionado el impacto que tuvo en el prelado las noticias de la villa de Atlixco. Entonces, ¿por qué ahora que se presentaban algunos sucesos de considerable preocupación el prelado simplemente los hacía menos? La respuesta salta a la vista. Si bien el prelado reconocía un estado de inquietud social en algunas comarcas de su diócesis, también era consciente de que, al hacer lo mismo para la ciudad de Puebla, asentamiento con mayor densidad de población en el obispado (Gerhard, 1981), permitiría que un funcionario leal al virrey — fuera este el conde de Galve o no- estuviese presente en la jurisdicción diocesana de manera permanente.

Don Manuel sabía que la presencia de un nuevo agente nombrado por el Superior Gobierno ocasionaría problemas entre la población de su diócesis. Podía, incluso, representar una nueva amenaza a la jurisdicción eclesiástica ya que no existían garantías de que, con la salida del conde de Galve, el Superior Gobierno desistiría en sus intentos por hacerse de los recursos. Por lo tanto, se volvía necesario responder a la orden del Consejo de Indias con el fin de refutar las opiniones del Real Acuerdo. Sin embargo, todo parece indicar que el prelado no tuvo prisa en remitir su parecer a Madrid, pues como se ha observado su correspondencia está fechada en el año de 1697. ¿Habrá sido una estrategia explícita de Manuel Fernández de Santa Cruz el despachar su respuesta lo más tarde posible, o la tardanza de las noticias obedeció a circunstancias y factores ajenos al obispo?

Otro aspecto interesante es la exaltación que hace don Manuel de su investidura. En su correspondencia pudimos percatarnos de que el prelado no solo menciona el haber intervenido en los acon- 
tecimientos de 1696, también afirmó que la principal razón por la que la ciudad de Puebla se había mantenido en relativa tranquilidad hasta ese momento se debía a su propia actuación. Es decir, reivindica su papel y el de su investidura como la máxima autoridad de la ciudad de Puebla capaz de mantener en paz a su rebaño. De hecho, pareciera que Manuel Fernández de Santa Cruz llega a postular la preminencia de la autoridad eclesiástica sobre el ámbito secular. En contraste con las autoridades civiles, de las que se mantenía cierto recelo y desconfianza, era evidente el cariño que sentía la población de la ciudad de Puebla por su prelado, razón que los mantenía tranquilos y en paz. En tanto, la intervención de las autoridades virreinales había ocasionado severas tensiones y alimentado el polvorín del tumulto. Respecto al primer punto tenemos que darle la razón al obispo, ya que fue principalmente su intervención en las problemáticas de la urbe la que había contenido el germen de las pasiones entre los poblanos. El obispo alimentó a la vecindad con los granos de las trojes eclesiásticas, veló porque se remediara inmediatamente la falta de agua en la ciudad, atendió a los convalecientes de la diócesis durante la plaga de sarampión procurando que los hospitales contaran con los insumos y el personal necesario y, finalmente, apaciguó las tensiones en las calles de la ciudad como consecuencia de un pleito entre comerciantes y regidores (Celaya Nádez, 2010; Alfaro Ramírez, 2001; Torres, 1999; Flores Sosa, 2020).

\section{CONSIDERACIONES FINALES}

La carestía que se experimentó a finales del siglo XVII en la Nueva España fue un fenómeno que trajo consigo severas consecuencias. La falta de trigo y maíz provocó la hambruna en la población novohispana, particularmente sufrida en los sectores más menesterosos. Fue tal la incertidumbre del estado general de cosas y el miedo a morir de hambre entre los vecinos de las villas y ciudades 
novohispanas que en poco tiempo propició el desarrollo de actos de violencia, tal y como lo ponen de manifiesto los tumultos en las ciudades de México y Tlaxcala en junio de 1692. Tal panorama social obligó a las autoridades del reino, tanto seculares como eclesiásticas, a tomar medidas que permitieran dar solución a tan severa problemática y evitaran el desarrollo de nuevos escenarios de violencia. Sin embargo, asumir tal reto resultó de lo más complejo y complicado. En gran medida la crisis frumentaria obligaba a las autoridades novohispanas a desarrollar acuerdos donde predominase el consenso, la colaboración y cooperación de las diferentes jurisdicciones. No obstante, esto resultaba del todo difícil de lograr, pues era evidente que las medidas implementadas no tendrían el mismo impacto en las diferentes poblaciones. Resultaba igualmente complicado el conseguir la formación de un consenso generalizado en todas las figuras de autoridad, pues no todas coincidían en los mismos puntos de vista. Por lo tanto, no es de sorprender, que el estado de carestía originara también un espacio de conflicto entre autoridades.

Uno de los casos más notorios fue el enfrentamiento entre el virrey Gaspar de la Cerda Silva y Mendoza, conde de Galve, y el obispo de Puebla Manuel Fernández de Santa Cruz. Como se señaló líneas arriba, el meollo del conflicto estuvo en los empeños del virrey por abastecer a la ciudad de México con las simientes de la diócesis poblana. Sin embargo, estas medidas resultaban contraproducentes para la población de aquel obispado, igualmente afectado por el estado de cosas. Entre los asentamientos afectados se encontraba la ciudad de Puebla de los Ángeles, segunda ciudad más importante del reino. No se puede dejar de mencionar, además, el grado de coerción con que se ejecutaban los despachos virreinales, lo que amenazaba con encender el polvorín de la violencia. Por lo tanto, no debe sorprendernos que la principal autoridad del obispado, el prelado Manuel Fernández de Santa Cruz, saliera en defensa de su jurisdicción. Si bien el obispo no se oponía rotundamente a las medidas del virrey, el prelado estaba en desacuerdo con la regularidad con la que 
se realizaban los traslados de las fanegas de trigo a la corte mexicana, no se diga de las formas en cómo se ejecutaban los despachos virreinales. De suerte que el obispo llegó a oponerse a la aplicación de los mandamientos del virrey, llegando al punto de utilizar las censuras como principal forma de disuasión. Fue tal la defensa del prelado de su jurisdicción que, en más de una ocasión, el virrey tuvo que dar marcha atrás a sus despachos y proyectos.

Sin embargo, el conde de Galve no se rindió en sus empeños. Como última medida, el virrey, con la colaboración de la Real Audiencia, despachó correspondencia al Consejo de Indias con el fin de denunciar el estado social de la ciudad de Puebla, sugiriendo además la aplicación de ciertas medidas. En concreto, ante la «agitación social poblana», el Superior Gobierno sugería nombrar a un ministro togado para que se trasladara a la ciudad de Puebla y ejerciera el cargo de Justicia Mayor. A pesar de lo referenciado en la correspondencia, nosotros consideramos que esta medida tenía una intención oculta. El introducir en la jurisdicción poblana a un agente cercano al círculo del virrey con la finalidad de garantizar la ejecución rápida y expedita de los mandamientos del virrey (incluyéndose, entre ellos, los despachos de traslado de fanegas y la tasación en el precio del trigo). De otra manera no se puede explicar el cambio de actitud del conde de Galve respecto a la situación social en el obispado de Puebla. Explicaría además el afán del Superior Gobierno por no destituir al impopular Agustín de Lezaca y Urdamibia en el cargo de alcalde mayor. Tampoco se puede ignorar el hecho de que en esta solicitud al Consejo se encontraban inmiscuidos algunos de los agentes del virrey encargados de realizar los mencionados traslados. El virrey tenía esperanzas de que, ante las denuncias de un estado de gravedad social, los concejeros respaldarían su propuesta de manera expedita. Sin embargo, no contó con la determinación de aquellos en solicitar el parecer del prelado, mucho menos con el nombramiento de Manuel Fernández de Santa Cruz como su sucesor interino. 
Por su parte, el prelado refutó las premisas del Real Acuerdo pues aseguró que estos no eran de la gravedad que denunciaba el virrey. Por más extraño que pueda parecer, a pesar de ser el personaje que más acusó el posible desarrollo del motín, el prelado fue el primero en minimizar los hechos acaecidos en la ciudad de Puebla. La razón se debía a que era consciente del efecto que traería la propuesta del Real Acuerdo mexicano: el afianzamiento de la presencia virreinal en aquella jurisdicción. Ante la preocupación del posible impacto social y político que ello pudiese generar, el prelado tomó la determinación de mostrar que la ciudad de Puebla se encontraba en paz. A pesar de que esto representó una evidente contradicción a su reciente postura, tal argumentación le permitió reivindicar la investidura que detentaba Fernández de Santa Cruz, así como el papel que su persona jugó en toda aquella situación. Don Manuel no solo expuso que su intervención fue relevante durante los años de carestía, sino que fue debido a ello, y solo a ello, que la vecindad de Puebla se mantenía en paz y quietud.

Las cartas que aquí se reseñaron ponen de manifiesto que el enfrentamiento entre el virrey de Nueva España y el obispo de Puebla se extendió aún más de lo que en investigaciones pasadas pudimos pensar. Muestran, además, el papel que jugaron, en este particular, las máximas autoridades de la monarquía española como la última instancia encargada de dictaminar lo más conveniente. Si bien no fue necesaria una sentencia del Consejo de Indias, pues el nombramiento de un nuevo virrey fue el aparente medio para dar solución al enfrentamiento, lo cierto es que las primeras determinaciones del cuerpo colegiado ponen en evidencia hacia dónde se inclinaría la balanza. La solicitud al prelado Santa Cruz para que externara su parecer muestra en gran medida los vínculos que existían entre el obispo de Puebla y el Consejo. Recordemos además que este obispo, como todos los prelados, formaban parte de las redes clientelares de dicho cuerpo colegiado, teniendo entre sus títulos el de «Consejeros de su Majestad» (Mazín, 2012a). De la misma mane- 
ra, esta determinación muestra la poca confianza que había para la persona del conde de Galve, debilitada quizá por las denuncias emprendidas por diferentes personajes y autoridades luego del tumulto de la ciudad de México (Silva Prada, 2007). Con base en lo señalado, todo parece indicar que el conde de Galve tenía pocas posibilidades de que su propuesta pudiera ser aprobada por el Consejo de Indias. Finalmente, todo esto nos permite constatar la preponderancia y poder que alcanzó el obispo Manuel Fernández de Santa Cruz por aquella época. No solo logró interponerse de manera efectiva a los proyectos y afanes del virrey. También logró ganarse la confianza y respaldo de los consejeros siendo la principal prueba de ello su nombramiento como virrey interino de la Nueva España en sustitución del conde de Galve. Cargo al que finalmente renunció.

\section{Archivos}

Archivo General de Indias (AGI)

México 346. El Real Acuerdo de México informa a vuestra Majestad sobre el mal estado de la ciudad de los Ángeles por los habitantes de la mucha plebe de que se compone, ocasionada de la timidery poca actitud de su alcalde mayor y poco o ningún respeto que se tiene a la justicia, 5 de enero de 1696, ff. $1312-1313 \mathrm{v}$.

México 346. El obispo de la Puebla responde a una Real Cédula de Vuestra Majestad en que se pide informe sobre la representación que hace el Real Acuerdo de la ciudad de México a Vuestra Majestad, tocante a Puebla y su alcalde mayor, 25 de mayo de 1697, ff. 1322-1326v.

Biblioteca Palafoxiana (BP)

Libro 32389. Mandato del Conde de Galve para que se ejecute la permisión de los trigos cogidos en Atlixco, Manuscritos, Documento 32389/015, ff. 266f-267f.

Libro R478. Correspondencia del obispo al virrey sobre el permiso de sembrar trigo blanquillo, Manuscritos, Documento R478/110, ff. 236f-236v. 
Libro R469. Memorial del obispo de Puebla sobre la defensa de los eclesiásticos a favor de los labradores, quienes tienen que enviar sus cosechas a la ciudad de México, Manuscritos, Documento R469/035, ff. 161f-161v.

Libro R469. Carta del obispo de Puebla al Conde de Galve sobre la presencia de Miguel Calderón en Puebla para adelantar la remisión de trigo eclesiástico a México, Manuscritos, Documento R469/027, f. $148 f$.

Libro R469. Consulta del oidor Miguel Calderón al obispo de Puebla sobre los precios fijos del trigo a los eclesiásticos, Manuscritos, Documento R469/030, ff. $152 \mathrm{f}-154 \mathrm{v}$.

Libro R469. Respuesta al oidor Miguel Calderón de la Barca del obispo sobre los inconvenientes que tienen los eclesiásticos a la tasación del precio del trigo y su escasez: Manuscritos, Documento R469/016, ff. 112f-116v.

\section{REFERENCIAS}

Alfaro Ramírez, Gustavo (2001). «El abasto de cereales en la Puebla del siglo XVII. El trigo blanquillo, la alhóndiga y el "pósito" tocinero». En: Francisco Cervantes Bello (coord.). Las dimensiones sociales del espacio en la historia de Puebla (XVII-XV III). Puebla: Benemérita Universidad Autónoma de Puebla, pp. 91-110.

Calvo, Thomas (2016). «Algunas historias de granos en medio de fluctuaciones planetarias: México y Cartagena de Indias en 1690-1692». En: Luis Alberto Arrioja Díaz Viruel et al. (eds.). Clima, desastres y convulsiones sociales en España e Hispanoamérica. Siglos XVII-XX. Zamora: El Colegio de Michoacán; Universidad de Alicante, pp. 269-294.

CaÑeque, Alejandro (2018). Un cuerpo de dos cabezas. La cultura política del poder en la Nueva España. Siglos XVI y XVII. México: Ediciones Educación y Cultura.

Celaya Nádez, Yovana (2010). Alcabalas y situados. Puebla en el sistema fiscal imperial. 1638-1642. México: El Colegio de México. 
UN OBISPADO BAJO LA MIRA DEL VIRREY Y UN PRELADO CELOSO DE SU JURISDICCIÓN. LOS PARECERES DEL conde de Galve y Manuel Fernández de Santa Cruz ante el Consejo de Indias: 1696 y 1697

Contreras, Carlos (et al.) (1993). Puebla. Textos de su historia. México: Gobierno del Estado de Puebla; Instituto de Ciencias Sociales y Humanidades UAP.

Escamilla, Iván (2002). «La caridad episcopal: El Hospital de San Pedro de Puebla en el siglo XVII». En: Montserrat Galí Boadella (ed.). El Mundo de Las Catedrales Novohispanas. Puebla: Benemérita Universidad Autónoma de Puebla, pp. 239-252.

Flores Sosa, Emmanuel Michel (2020). Un dechado de príncipe eclesiástico. Puebla de los Angeles durante la gestión del obispo Manuel Fernández de Santa Cruz. (1675-1699). Tesis de doctorado. México: El Colegio de México.

Galí Boadella, Montserrat (2001). «El patrocinio episcopal en la ciudad de Puebla : El caso del obispo Manuel Fernández de Santa Cruz, 1677-1699». En: Actas del III Congreso Internacional del Barroco Iberoamericano. Sevilla: Universidad Pablo de Olavide, pp. 89-110.

Gerhard, Peter (1981). «Un censo de la Diócesis de Puebla en 1681». Historia Mexicana, El Colegio de México, vol. 30, núm. 4, pp. 530-560.

Gutiérrez Lorenzo, María del Pilar (1993). De la corte de Castilla al virreinato de México: El Conde de Galve (1653-1697). Madrid: Excma. Diputación Provincial Guadalajara.

Mazín, Óscar (2012a). «Una Jerarquía Hispánica. Los obispos de la Nueva España». En: Víctor Gayol (coord.). Formas de Gobierno en México. Poder Político y Actores Sociales a través del Tiempo. Zamora: El Colegio de Michoacán, A. C., pp. 121-142.

Mazín, Óscar (2012b). «Representaciones del poder episcopal en Nueva España (siglo XVII y primera mitad del XVIII)». En: Óscar Mazín (ed.). Las representaciones del poder en las sociedades hispánicas. México: El Colegio de México, pp. 373-401.

Paredes Martínez, Carlos Salvador (1991). La región de Atlixco, Huaquechulay Tochimilco. La sociedady su agricultura en el siglo XVI. México: Centro de Investigaciones y Estudios Superiores en Antropología Social. 
PARKER, Geoffrey (1981). Europa en crisis. 1598-1648. México: Editorial Siglo XXI.

PARKER, Geoffrey (2013). Global crisis. War climate change and catastrophe in the seventeenth century. Londres: Yale University Press.

Prem, Hanns (1978). Milpa y hacienda. Tenencia de la tierra indígena y española en la cuenca del alto Atoyac, Puebla, México (1520-1650). México: Centro de Investigaciones y Estudios Superiores en Antropología Social.

Salazar Andreu, Juan Pablo (2005). Obispos de Puebla. Periodo de los Austrias (1521-1700). México: Editorial Porrúa.

Salazar Andreu, Juan Pablo (2016). «Obispos Angelopolitanos destacados en su servicio a la Corona (Periodo de los Austria y los Borbones)». En: Sigrid María Louvier Nava (coord.). La Puebla de los Ángeles en el virreinato. Puebla: Universidad Popular Autónoma del Estado de Puebla, pp. 61-96.

Salazar Andreu, Juan Pablo (2020). «El prelado que rechazó ser arzobispo y virrey: Manuel Fernández de Santa Cruz y Sahagún». Hipogrifo: Revista de literatura y cultura del siglo de oro. Madrid, Instituto de Estudios Auriseculares, vol. 8, núm. 2, pp. 781-791.

SigüenZa y Góngora, Carlos (1932). Alboroto y motín de México del 8 de junio de 1692. México: Talleres Gráficos del Museo Nacional de Arqueología, Historia y Etnografía.

Silva Prada, Natalia (2007). La politica de una rebelión. Los indigenas frente al tumulto de 1692 en la ciudad de México. México: El Colegio de México.

Torres, Fray Miguel de (1999). Dechado de principes eclesiásticos que dibujó con su ejemplar, virtuosa y ajustada vida el Ilusrísimo y Excelentísimo Señor Doctor Don Manuel Fernández de Santa Cruzy Sahagún. Edición facsimilar. México: Sociedad Mexicana de Bibliófilos A. C.

Fecha de recepción: 23 de noviembre de 2020.

Fecha de evaluación: 7 de enero de 2021.

Fecha de aceptación: 15 de febrero de 2021.

Fecha de publicación: 30 de junio de 2021.

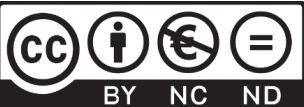

